\title{
Thermal Economy Analysis Model with Matrix Method for the Secondary Loop of PWR Nuclear Power Station
}

\author{
Li Yongling \\ North China Electric Power University, \\ North China Baoding Electric Power Voc. \& Tech. College \\ Baoding, Hebei, China
}

\begin{abstract}
According to characteristics of Pressurized Water Reactor ( PWR ) nuclear power station, the two-stage moisture separator reheater (MSR) model was proposed with thermal equilibrium equation and mass conservation equation, finally the thermo-economy analysis model with matrix equation for secondary loop was put up. Based on the model, the thermal economy influence values of the auxiliary steamwater are calculated and compared with those of habitual thermal balance method (HTBM). The results indicate that the model presented in the article was correct; it is available and convenient for computer coding and online calculating. The matrix analysis method can provide theoretical basis for simulating of the secondary loop thermal system for PWR nuclear power station.
\end{abstract}

Keywords-Pressurized water reactor, secondary loop, thermal economy, state equation, Mechanism modeling

\section{INTRODUCTION}

At present the main type of nuclear power station is PWR, it occupies about over 50 percent of the total installed capacity [1]. The economy of secondary loop directly affects the efficiency of the whole unit. Its structure in the unit is more complex compared with the coal fired one, which used the regenerative cycle with steam reheat. So it is difficult for researchers to analyze the economy of secondary loop in PWR nuclear power station.

There are several thermal system analysis methods, such as HTBM, the cycle function method, equivalent heat drop method and matrix method and so on [2-4]. HTBM is the basis method. Equivalent heat drop analysis method can carry out local quantitative analysis concisely and conveniently, which has been widely applied in thermal system analysis research of nuclear power station [59].When the local parameters or structure changing, in order to avoid calculating the comprehensive thermodynamic system it is necessary for us to find a clear, convenient, and simple quantitative economy analysis method. The theoretical study of this question is comparatively less. Therefore, the thermo-economy analysis model with matrix method in PWR nuclear power station is proposed.

\section{THERMAL ECONOMY ANALYSIS MODEL WITH MATRIX METHOD}

\section{A. System Introduction}

\author{
Huang Yu, Ma Jin, Wang Binshu \\ North China Electric Power University, \\ Baoding, Hebei, China
}

Compared with the coal fired power plant, the secondary loop in nuclear power stations adopts the saturated steam circle, so the high-pressure (HP) cylinder exhaust steam should separate from the moisture separator before entering the reheater. And the intermediate reheat steam is always the main steam [10]. Therefore, separatorsdesigned to gather small water droplets from steam and separate those from the pipe flow. There is also the moisture separator reheater (MSR) in some nuclear power station. Accordingly, the drainage of MSR must enter into the high pressure heater (HPH) and low pressure heater (LPH) in regenerative system. As shown in Figure. 1, the saturated water from the moisture separator flows into the deaerator; the saturated steam enters into lower-pressure cylinder after reheating by reheat steam, some main steam and part of the first-stage steam extraction ; the drainage enters into the HPH.

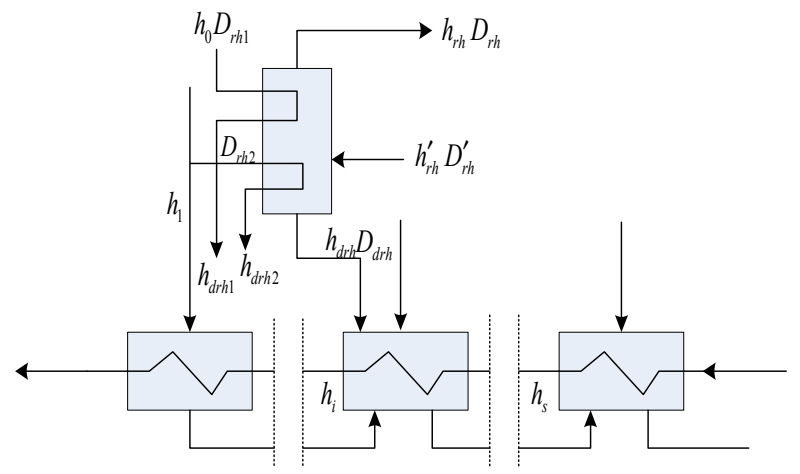

Figure 1. The system of HPH and MSR in secondary loop

\section{B. MSR model}

The quality equations for two-stage MSR are expressed in formulas (1)(2).

$$
\begin{gathered}
D_{r h}^{\prime}=D_{d r h}+D_{r h} \\
D r h=D_{0}-\sum_{i=1}^{m} D_{i}-D_{r h 1}-D_{r h 2}-\sum_{j=1}^{n} D_{f i}
\end{gathered}
$$

The Thermal equilibrium equation can be presented by below formula,

$$
\begin{aligned}
& h_{r h}^{\prime} D_{r h}^{\prime \prime}+\left(h_{0}-h_{d r h 1}\right) D_{r h 1}+\left(h_{1}-h_{d r h 2}\right) D_{r h 2} \\
& -D_{d r h} h_{d r h}=h_{r h} D_{r h}
\end{aligned}
$$


Where, $D_{\text {rh }}^{\prime}$ is HP cylinder exhaust steam flow; $h_{\text {rh }}^{\prime}$ is HP cylinder exhaust steam enthalpy; $D_{\text {drh }}$ is saturated water flow from the MSR; $h_{\text {drh }}$ is saturated water enthalpy from the MSR; $h_{\mathrm{rh}}$ is saturated steam enthalpy from the MSR; h0 is main steam enthalpy; $h_{1}$ is the first-stage extraction steam enthalpy; $D_{\text {rh1 }}$ is first-stage reheat steam flow; $D_{\text {rh2 }}$ is the second-stage reheat steam flow; $D_{\mathrm{drh} 1}$ is the first-stage reheat drain flow; $D_{\mathrm{drh} 2}$ is the second-stage reheat drain flow; $h_{\mathrm{drh} 1}$ is the first-stage reheat drain enthalpy; $h_{\mathrm{drh} 2}$ is the second-

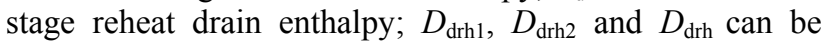
considered as auxiliary water flow. The thermal equilibrium equation, taking HPH $i$ as an example, is established in formula (4).

$$
\begin{aligned}
& \sum_{k=1}^{i-1} D_{d k} \gamma_{i}+\left(D_{i}-\sum D_{f i}+D_{d r h}\right) q_{i} \\
& +D_{f d r h}\left(h_{f d r h}-h i\right)-\sum D_{f i}\left(h_{f i}-h_{i}\right)=D_{w i} \tau_{i}
\end{aligned}
$$

If the serial number of LPH is $i$, the nearest collection type heater's serial number is $s$, the equations are shown in (5). Where, $q_{\mathrm{i}}, \tau_{\mathrm{i}}$ and $\gamma_{\mathrm{i}}$ mean steam extraction heat, drainage heat, feed-water enthalpy rise.

$$
\begin{aligned}
& \sum_{j=s+1}^{i-1}\left(D_{j}+D_{f j}\right) \gamma_{i}+D_{i} q_{i}=D_{c}^{\prime} \tau_{i} \\
& D_{c}^{\prime}=D_{0}-D_{r h 1}-D_{r h 2}-D_{d r h}-\sum_{k=1}^{s}\left(D_{k}+D_{j k}\right)
\end{aligned}
$$

\section{The steam-water distribution matrix equation}

In the analysis of thermal system, the matrix analysis method has been widely applied because of its characteristics of concise expression and easy conversion into mathematic problems [11-15]. According to thermal equilibrium equations and quality equations of heaters in secondary loop thermodynamic system, the matrix equation of thermal equilibrium is obtained in (6).

$$
[A][D]+[A]\left[D_{\mathrm{f}}\right]+\left[Q_{\mathrm{f}}\right]=\left[Q_{\tau}\right]
$$

Where, $[A]$ is the steam-water distribution matrix of main system, which includes the steam extraction, drainage, feed water, and the auxiliary steam-water system includes the steam leakage, first-stage reheat steam, second-stage reheat steam, the drainage of MSR and feed water pump enthalpy rise. $[A]$ matrix can be expressed as lower triangular matrix. $[D]$ is shown as a column of steam extraction flow, $\left[D_{\mathrm{f}}\right]$ is also shown as a column, the elements means the sum of auxiliary steam-water flow of heater $i$. The matrix $\left[Q_{\mathrm{f}}\right]$ means the energy change matrix as a result of the auxiliary steam-water flow of the heater system. The matrix $\left[Q_{\tau}\right]$ means the corresponding feed water energy change of heater $i$, which can be expressed by the product of feed-water enthalpy rise $\tau_{\mathrm{i}}$ and outlet flow $D_{\text {wi. }}$.
Generally, economic performances of thermodynamic system are calculated on the basis of the main steam flow $D_{0}$. For the secondary loop thermal system of PWR nuclear power station, if the main steam enthalpy is $h_{0}$, turbine exhaust steam enthalpy is $h_{\mathrm{c}}$, the power equation is expressed in (7), when steam extraction of heater and gland leakage steam flows left the steam path of turbine.

$$
N=D_{0}\left(h_{0}+\sigma-h_{c}\right)-\sum_{i=1}^{p} D_{i} \widetilde{h}_{i}^{\sigma}-\sum_{j=1}^{q} D_{j} \tilde{h}_{j}^{\sigma}+\sum_{k=1}^{s} D_{k} \tilde{h}_{k}^{\sigma}
$$

Where, the expression $D_{0}\left(h_{0}+\sigma-h_{\mathrm{c}}\right)$ represents the

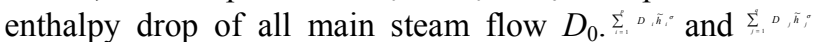
mean the power shortage of the steam extraction flows and auxiliary steam flows. $\sum_{k=1}^{s} D \tilde{h}_{k}^{\sigma}$ represents the power shortage of other steam leakage flow. $\tilde{h}^{\sigma}$ means the energy change of small steam flow, when it left from HP cylinder, $\widetilde{h}_{j}{ }^{\sigma}=h_{j}+\sigma-h_{c}$, and if it departed from IP and LP cylinders, $\widetilde{h}_{i}{ }^{\sigma}=h_{j}-h_{c} \cdot \sigma$ represents the steam heat in reheater.

Compared with the coal-fired power plant, the reheat steam comes from main steam, and did not absorb the external heat, so the circulation heat does not contain the item $\sigma$ (reheater heat) for the secondary loop thermal system. The Factors influencing the working medium heat are the main feed water and SG blow down flow. According to energy balance, the heat equation is expressed,

$$
Q=D_{0}\left(h_{0}-h_{f w}\right)+D_{b l}\left(h_{b l}-h_{f w}\right)
$$

Equation (6), (11), (12) are known as the thermal economic state equations of the secondary loop of PWR nuclear power station. The equations are basis equations, which reflect the heater types and drainage connection.

D. Local quantitative analysis model

The cycle efficiency is one of the thermal economy analysis indicators. According to the thermal economy local quantitative analysis method based on the matrix equation, as long as we fill in related matrix by the rules, the efficiency change of the system can be calculated depending on setting the corresponding parameters in the matrix of the effect factors we analyzed to 0 .

If the cycle efficiency for actual system is $\eta_{0}$, it can be used the formula expresses in (9). The cycle efficiency which ignored one or several auxiliary steam-water disturbances is expressed as $\eta_{0}^{\prime}$. As a result the influence relative values of these auxiliary steam-water flows are calculated by the formula. The overall efficiency of nuclear power station can be expressed in (11).

$$
\begin{gathered}
\eta_{0}=N / Q \\
\Delta \eta^{\prime}=\left(\eta^{\prime}{ }_{0}-\eta_{0}\right) / \eta_{0} \times 100 \% \\
\eta_{\mathrm{as}=}=\eta_{\mathrm{R}} \cdot \eta_{\mathrm{sg}} \cdot \eta_{\mathrm{p}} \cdot \eta_{0} \cdot \eta_{\mathrm{m}} \cdot \eta_{\mathrm{g}}
\end{gathered}
$$

Therefore, the nuclear reactor fuel consumption $b_{a s}(g /(k W \cdot h))$ can be represented as, The change of nuclear reactor fuel consumption can be determined by the formula (13) as the cycle thermal efficiency alters. 


$$
\begin{gathered}
b_{a s}=\frac{0.054}{\eta_{a s}}=\frac{0.054}{\eta_{R} \eta_{s g} \eta_{P} \eta_{0} \eta_{m} \eta_{g}} \\
\Delta b_{a s}=b_{a s}-b_{a s}^{\prime}=\frac{0.054}{\eta_{R} \eta_{s g} \eta_{P} \eta_{0} \eta_{m} \eta_{g}} \times\left(\frac{\Delta \eta_{0}}{\eta_{0}}\right)=b_{a s} \times \delta \eta_{0}
\end{gathered}
$$

Therefore, the relative value $\delta \eta_{0}$ can be available to indicate the thermal economic influence of these auxiliary steam-water disturbances.

\section{RESULTS OF ONE EXAMPLE ON MATRIX EQUATION}

In order to verify the correctness and accuracy of the model, a numerical example of a PWR nuclear power

station is calculated, as is shown in Figure. 2 (some parameters are listed in tab.1and tab.2). There are some structural features, such as single-axis, four-cylinder, sextuple-flow, double-stage reheat. Some parameters of the secondary loop thermal system is listed following: the pressure and temperature of main steam are $6.41 M p_{\text {a }}$ and $279.9^{\circ} \mathrm{C}$, reheated steam pressure and is temperature are $0.978 M p_{\mathrm{a}}$ and $265.2^{\circ} \mathrm{C}$, the reheat heat from main steam and HP cylinder exhaust steam to MSR are $\sigma_{\mathrm{zr}, 1}=1557.5$ $\mathrm{kJ} / \mathrm{kg}$ and $\sigma_{\mathrm{zr}, 2}=1671 \mathrm{~kJ} / \mathrm{kg}$.

Fill in the matrixes depending on the rules of state equation for the secondary loop thermal system of PWR nuclear power station established in this paper. The main matrixes, power equation and heat equation are listed below.

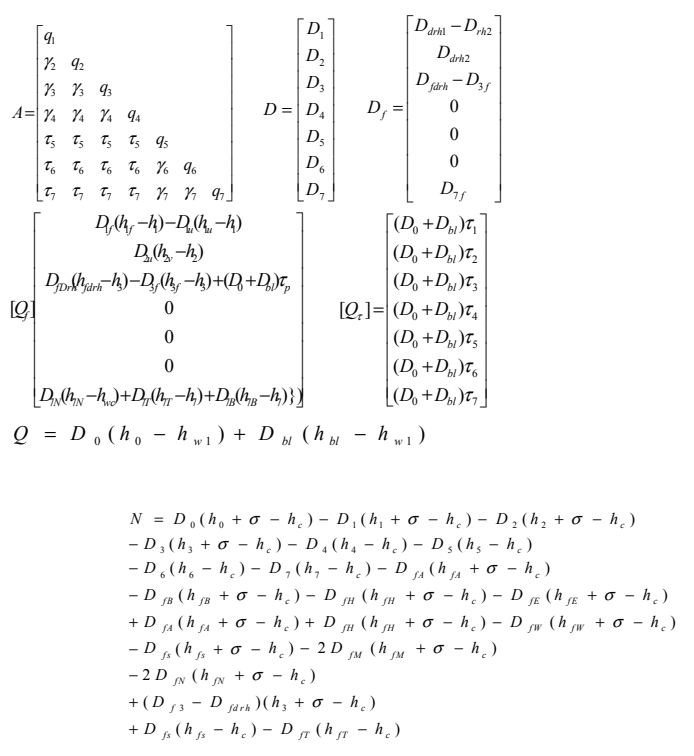

According to above matrixes, we can determined the main steam flow $D_{0}$ and steam extraction flows, $D_{0}, D_{1}, D_{2}, D_{3}, D_{4}, D_{5}, D_{6}, D_{7}$. Depending on the quality equations of MSR, the reheat steam flow can be confirmed. According to the calculation results of the power and heat equation, we can calculate the efficiency $\eta_{0}$. Depending on setting the corresponding parameters we analyzed in the matrix to 0 , the changed efficiency $\eta^{\prime}{ }_{0}$ can be calculate. As a result the thermal economy influence relative values $\Delta \eta_{0}^{\prime}$ is calculated. Calculation results are shown in tab. 4.

The results show that the matrix results are in good agreement with those of HTBM, which proves that the matrix method presented in this dissertation is correct and available. The matrix fully reflects the thermal economy influence of main system and auxiliary system. Each submatrix has explicit physical meanings and strong regularity, so that it can make the overall computation and local analysis clear and simple, and suitable for computer programming.

\section{CONCLUSIONS}

According to characteristics of PWR nuclear power station, the secondary loop thermal system using the twostage MSR was mainly analyzed. The thermal equilibrium equation and mass conservation equation on heaters of the secondary loop thermal system were proposed; finally the thermo-economy system state equation for it was put up. The implicit topological structure of matrix reflects the heater types and drainage connection. The accuracy and practicability of the method was verified by a calculation example. The matrix equation with the great regularity is convenient to fill in and suitable for the computer to calculate in particular with MATLAB. The matrix analysis method can provide theoretical basis for thermal economy research and system simulation of the secondary loop thermal system for PWR nuclear power station.

\section{ACKNOWLEDGMENTS}

Project supported by the Fundamental Research Funds for the Central Universities under Grant 10MG25, and also supported by the Young Teachers Fund for Scientific Research in North China Electric Power University (200811013).

\section{REFERENCES}

[1] Zhu hua. Automatic energy and nuclear power stations. Hangzhou: Zhejiang University Press, 2009.10:110-112.

[2] Lin Wanchao.Energy-saving analyses method of thermal power plant thermal system $[\mathrm{M}] . \mathrm{Xi}$, an: $\mathrm{Xi}{ }^{\prime}$ an Jiaotong University Press, 1994:33-40(in Chinese) .

[3] Zheng Tikuan. Thermal power plant [M]. Beiing: China Electric Power Press,2001:144-150 (in Chinese) .

[4] Ma Fangli. Energy-saving analyses principle of thermal power plant thermal system [M]. Beiing:China Electric Power Press, 1992.

[5] Yan Junjie,Lin Wanchao, Deng Shimin. Research on thermoeconomics diagnostic method for the secondary-circuit of PWR nuclear cogeneration plant $[\mathrm{J}]$.Proceedings of the CSEE,2001,21 (8) :60-63(in Chinese) .

[6] Yan Junjie, Li Yunze. Research on thermo-economics analysis theory for thermal system of the secondary-circuit of PWR nuclear power station [J] .Proceedings of the CSEE,2000,20 (5) :5-8(in Chinese).

[7] Li Yunze, Yan Junjie, Lin Wanchao, et al. A linear element method for analyzing the secondary loop of a pressurized water reactor (PWR)nuclear power station[J].Journal of Engineering for Thermal Energy and Power, 2000,15(5):544-547(in Chinese). 
[8] Li Yunze,Yan Junjie,Lin Wanchao,et al.The equivalent heat drop method for the secondary-circuit analysis of PWR nuclear power station system[J].Turbine Technology,2000,42(1): 31-35(in Chinese).

[9] Li Jiangang,Li Liping,Yang Xiaokun.A study of steam-water flow distribution calculation for the secondary-circuit thermodynamic system of PWR nuclear power station[J].Turbine Technology, 2004,46(2):94-96(in Chinese).

[10] Sterman L S,Terlin S A,Sharkow A T.Thermal and Nuclear Power Stations.Moscow: Mir Publishers, 1986,200 308.

[11] Guo Jianglong,Zhang Shufang,Song Zhiping,et al.A matrix method for thermal system analysis in a power plant [J] .Proceedings of the CSEE,2004,24 (1) :205-210(in Chinese) .
[12] Zhang Chunfa,Zhang Suxiang,Cui Yinghong,et al. Thermo-economy state equation of modern power system [J]. Journal of engineering thermophysics,2001,22(6):665-667(in Chinese).

[13] Zhang Chun-fa, LI Juan. Quantitative study for the limitation of small disturbance theory on the step out of high-pressure heater[J]. Turbine technology. 2008, 2(1): 34-36.

[14] Chen Haiping.Calculation of thermodynamic system in power plant based on mass unit [D] .Baoding:North China Electric Power University,2002,4 (in Chinese) .

[15] Zhang Chunfa, Xie Fei, Li Yongling. Thermal economic state equation of $300 \mathrm{MW}$ air cooling unit [J].Electric Power Science and Engineering, 2005, 2:64-66.

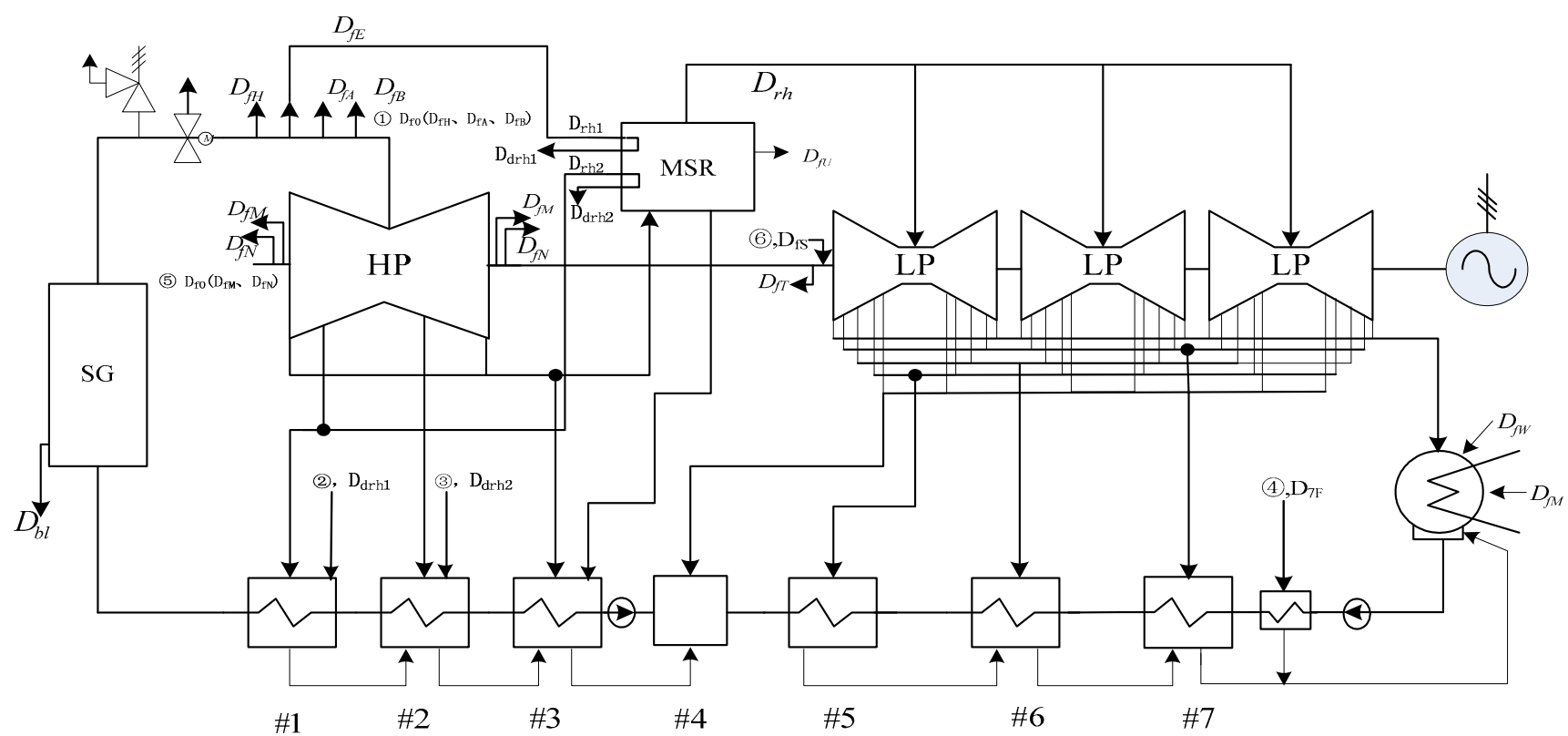

Figure 2. Flow chart of a PWR nuclear power station

TABLE I. MAIN ORIGINAL DATUM OF THE MAIN THERMODYNAMIC SYSTEM

\begin{tabular}{|c|c|c|c|}
\hline Heater Numbers & $q_{\mathrm{i}} /(\mathrm{kJ} / \mathrm{kg})$ & $\gamma_{\mathrm{i}} /(\mathbf{k J} / \mathbf{k g})$ & $\tau_{\mathrm{i}} /(\mathrm{kJ} / \mathrm{kg})$ \\
\hline 1 & 1734.9 & & 121.4 \\
\hline 2 & 1742.1 & 114.4 & 112.7 \\
\hline 3 & 1875.9 & 131.7 & 130.1 \\
\hline 4 & 2372.2 & 188.8 & 160.3 \\
\hline 5 & 2251.1 & & 84.7 \\
\hline 6 & 1943.7 & 105.0 & 104.8 \\
\hline 7 & 1456.9 & 60.8 & 62.5 \\
\hline
\end{tabular}

TABLE II. DATUM OF AUXILIARY STEAM-WATER SYSTEM

\begin{tabular}{|c|c|c|c|}
\hline Auxiliary steam & steam-water proportion & $h_{\mathrm{fi}} /(\mathrm{kJ} / \mathrm{kg})$ & $q_{\mathrm{fi}} /(\mathrm{kJ} / \mathrm{kg})$ \\
\hline (1) & $\alpha_{\mathrm{f} 0}=0.00092$ & 2772.8 & \\
\hline (2) & $\alpha_{d \mathrm{rh} 1}=0.0424$ & 1246.5 & 351.7728 \\
\hline (3) & $\alpha_{d \mathrm{rh} 2}=0.0440$ & 1037.3 & 257.0397 \\
\hline (5) & $\alpha_{\mathrm{fMN}}=0.00056$ & 2524.5 & \\
\hline (6) & $\alpha_{\mathrm{fS}}=0.00076$ & 2772.8 & \\
\hline
\end{tabular}


TABLE IV. THE THERMAL ECONOMY CALCULATING RESULTS (\%)

\begin{tabular}{lllll}
\hline & Item & \multicolumn{2}{c}{ Matrix method } & HTBM \\
\hline Actual cycle efficiency & & 32.9218 & 32.9218 \\
\hline & $(1)$ & 0.077068 & 0.077054 \\
\cline { 2 - 4 } $\begin{array}{l}\text { The influence on thermal economy with auxiliary steam-water } \\
\text { flows }\end{array}$ & (2) & 1.879634 & 1.879621 \\
\cline { 2 - 4 } & (3) & 1.362056 & 1.362043 \\
\cline { 2 - 4 } & (5) & 0.117035 & 0.117023 \\
\cline { 2 - 4 }
\end{tabular}

Published by Atlantis Press, Paris, France.

(C) the authors 